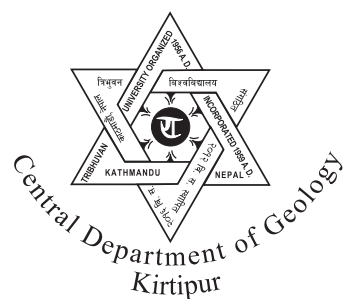

\title{
Magnetism and granulometry of Pleistocene sediments of Dhapasi section, Kathmandu (Nepal): implications for depositional age and paleoenvironment
}

\author{
*Pitambar Gautam1, Tetsuya Sakai², Khum Narayan Paudayal³, Sudarshan Bhandari³, \\ Babu Ram Gyawali4, Chinta Mani Gautam ${ }^{4}$ and Moti Lal Rijal5 \\ ${ }^{1}$ Creative Research Institution Sousei (CRIS), Hokkaido University, Sapporo, Japan \\ 2 Department of Geoscience, Shimane University, Matsue, Japan \\ ${ }^{3}$ Central Department of Geology, Tribhuvan University, Kirtipur, Kathmandu, Nepal \\ 42-Gha, Sanepa, Ring Road, Lalitpur, Kathmandu, Nepal \\ ${ }^{5}$ Center for Applied Geoscience, University of Tuebingen, Tuebingen, Germany
}

\begin{abstract}
A 28-m thick exposure of the younger stage deposits of Kathmandu Valley fluvio-deltaic deposits at Dhapasi has been studied for magnetic susceptibility (MS), remanent magnetization (RM), grain size characteristics of fine-grained sediments, and sedimentary fabric by anisotropy of magnetic susceptibility (AMS). In situ volume MS ( $\kappa$; in $10^{-3} \mathrm{SI}$ ) of the natural sediments ranges from 0.001 to 0.15 , with lower range $(<0.02)$ restricted to quartz-rich coarse sand, whereas the uppermost 20 -cm thick section affected by anthropogenic activity exhibits enhanced range (0.15-2). RM of specimens from some 80 levels reveals predominantly normal polarity except for a part of ca. $80 \mathrm{~cm}$ thick sandy silt, located about $6-\mathrm{m}$ above the base, yielding reverse polarity attributed to the Laschamp Reversal Event/Excursion (LRE) dated in literature at ca. $41 \mathrm{Ka}$. This inference, along with majority of other ${ }^{14} \mathrm{C}$ data, lends further support to the affinity of Dhapasi section to the Gokarna Formation (ca. $>45$ to $34 \mathrm{Ka}$ ).

Laser granulometry of fine-grained sediments from 76 levels reveals polymodal (2-4 modes) nature. With two prominent modes corresponding at 7.3 and $57.5 \mu \mathrm{m}$, these sediments plot into sandy silt, silt, and silty sand regions. MS correlates positively among broad grain size classes (i.e., increasing trend from sand through silt to clay). Mainly oblate susceptibility ellipsoids and low anisotropy degree shown by AMS data suggest a depositional fabric contributed by mainly paramagnetic minerals (e.g., phyllosilicates) responsible to low magnitudes of mass-specific MS $\left(5-15 \times 10^{-8} \mathrm{~m}^{3} \mathrm{~kg}^{-1}\right)$. Magnetic lineations or maximum susceptibility axes $\left(\kappa_{\max }\right)$ are inferred to be predominantly NNW to SSE below ca. 18-m level, but NNE to SSW above. Such difference points to shift of paleoflow during the sediment deposition, and together with slight differences in grain-size parameters, in two prominent intervals of prodelta deposits, suggests significant changes in the paleodrainage configuration and source-sink relationship.
\end{abstract}

\section{INTRODUCTION}

The Kathmandu intermontane basin consists of late Pliocene to Holocene fluvio-lacustrine, fluvial and fluvio-deltaic sediments resting unconformably over the Palaeozoic rocks of the Kathmandu Complex

*Corresponding author:

E-mail address: pgautam@cris.hokudai.ac.jp
(DMG 1980). Based on earlier mapping (Yoshida and Igarashi 1984; Yoshida and Gautam 1988), these sediments were divided into eight units. It is believed that following the deposition of the Lukundol Formation of late Pliocene to early Pleistocene age (Sakai H. et al. 2006; Goddu et al. 2007) throughout the basin, the Mahabharat range started to experience accelerated upheaval at ca. $1 \mathrm{Ma}$, and as a result the 
old lake started to shift northwards leading subsequently to the formation of a series of terrace deposits found today in the southern part of the Kathmandu Valley (e.g., Pyanggaon: 1,480-1,520 m, Chapagaon: 1,440-1,460 $\mathrm{m}$, and Boregaon: 1,410-1,430 m; Yoshida and Igarashi 1984). The upper part of the valley sediments exposed over the wide area in its central and northern part belong to the younger stage deposits called as the Gokarna Formation, Thimi Formation, and Patan Formation (Yoshida and Igarashi 1984), whose tops are demarcated by Gokarna (I: $1,380-1,390 \mathrm{~m}$; II: 1,350-1,370m), Thimi (1,330-1,340 m) and Patan $(1,300-1,320 \mathrm{~m})$ terraces (Sakai T. et al. 2006), assigned loosely between ca. 50 to $10 \mathrm{Ka}$ based on a number of ${ }^{14} \mathrm{C}$ radiometric dates (see Gautam et al. 2001 and references therein).

Detailed analyses of lithofacies, radiocarbon dates and magnetic polarity data led to revision of the lithostratigraphic divisions especially in the northern part of the Kathmandu Basin Group (name proposed by Sakai H. 2001) into the followings: Dharmasthali (partly older than $780 \mathrm{Ka}$, corresponding to the Tarebhir, the Lukundol and the Itaiti Formations in southern part of the basin), Kalimati (>10 Ka), Gokarna (50-34 Ka), Thimi (33-24 Ka), Tokha (19-14 $\mathrm{Ka})$, and Patan (14-10 Ka) Formations as shown in Fig. 1. Only the Kalimati Formation is distributed in the central basin, and appears to be the distal equivalent of the others.

This study is a part of an integrated magnetic, sedimentological and pollen analytical approach to better constrain the depositional age of the younger stage deposits, to device the field-based techniques for lateral correlation, and to decipher the depositional environment and paleoclimate based on research concentrated on the northern part of the Kathmandu valley (e.g., Gautam et al. 2001; Paudayal 2006; Sakai T. et al. 2006). Facies analysis of the younger stage deposits led to recognition of 5 distinct groups (I-III: delta plain; IV: delta front; and V: prodelta) in the fluvio-lacustrine and deltaic facies given below (Sakai T. et al. 2006).

I. Fluvial channel fill deposits (cross and parallellaminated sandy and lenticular sandy gravel beds; high-energy environment),

II. Marsh or flood plain deposits (black silt beds with intercalations of very fine to fine sand layers; relatively calmer hydraulic environment with intermittent deposition by low-energy streams),

III. Interdistributary bay deposits (black laminated or massive, often rich in diatoms and organic material, silt beds alternating with sand layers; deposition mainly from suspension with minor role of currents in crevasse-splay or crevasse-delta setting),

IV. Delta front deposits (sand, sandy gravel, or alternating sand and sandy silt beds with features typical to subaqueous deposition in area affected by wave-generation, and gravity-induced flow regime), and

V. Prodelta deposits (alternating sand and black silt beds, with or without traceable diatomaceous interbeds rich in organic material; deposition in open lake environment with intermittent supply of sand from traction or as a suspended load from the delta front).

The Gokarna terraces exhibit no remarkable traces of gradual fall in lake level such as the record of gradual decrease in the height of the delta front deposits. Hence, their formation is attributed to plug destruction (at the basin outlet in the Bagmati gorge situated in the south) that led to rapid fall in the lake level (Sakai T. et al. 2006). It is likely that Gokarna, Thimi and Patan terraces with their distinct heights result from at least 3 consecutive phases of significant plug destruction at the basin outlet.

\section{DETAILS OF INVESTIGATIONS AND RESULTS OBTAINED}

A ca. $28 \mathrm{~m}$ thick exposure of the Gokarna Formation (below Gokarna II terrace; altitude: ca. $1,358 \mathrm{~m})$ at a scarp at Dhapasi $\left(27^{\circ} 44^{\prime} 50^{\prime \prime} \mathrm{N}\right.$ and $\left.85^{\circ} 19^{\prime} 45^{\prime \prime} \mathrm{E}\right)$, situated NE of Basundhara at Ring Road, was measured in 2006 for this study. Paudayal (2006) described an earlier exposure comprising alternating layers of black and grey clay, silt, fineto coarse-grained arkosic sand, and gravel, where the thickness of clay and silt beds ranged from 0.3 to 3 $\mathrm{m}$, and the sand beds, often cross-bedded, were found to become thicker upward. Pollens extracted from carbonaceous clay/silt layers were used to suggest six pollen assemblage zones: GOK-I to GOK-VI, some of them into several subzones, from bottom to 
a)

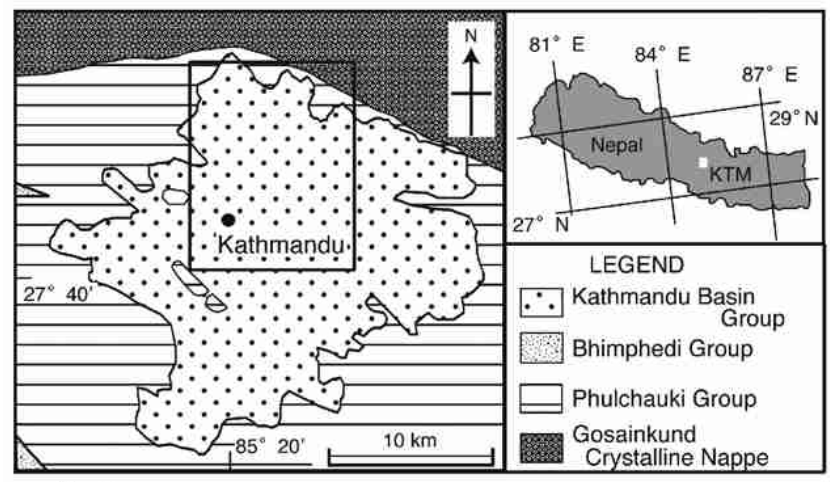

b)

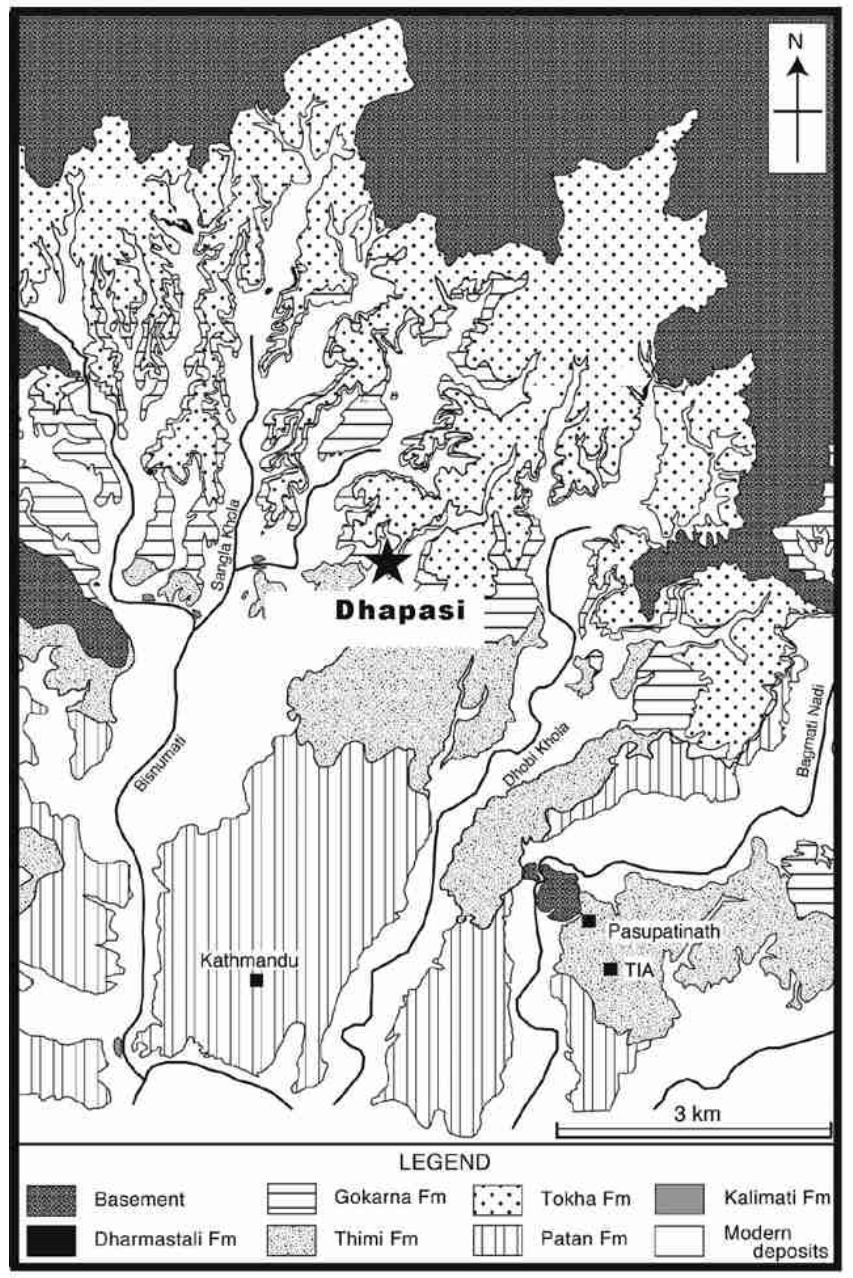

c)

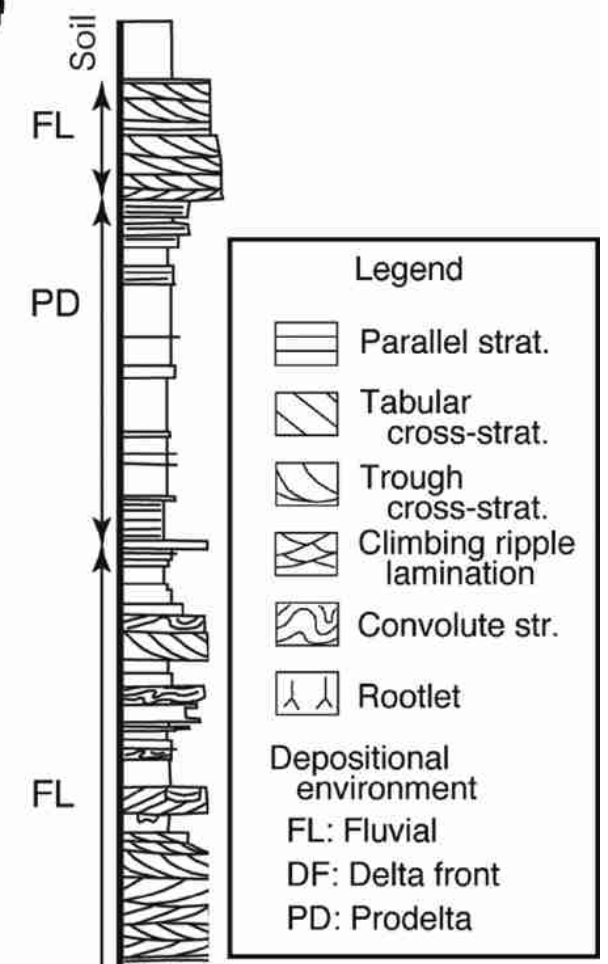

Fig. 1 (a) Index map showing the location of Kathmandu valley in the Nepal Lesser Himalaya. (b) Geological zonation of the northwestern part of Kathmandu valley characterized by widespread occurrence of the younger stage deposits. Star indicates the location of the Dhapasi section. (c) The columnar section at Dhapasi outcrop as of March 2009, with identification of fluvial (FL), delta front (DF), and prodelta (PD) depositional environments. M, S, G in at the base of the lithological column denote mud, sand and gravel, respectively 


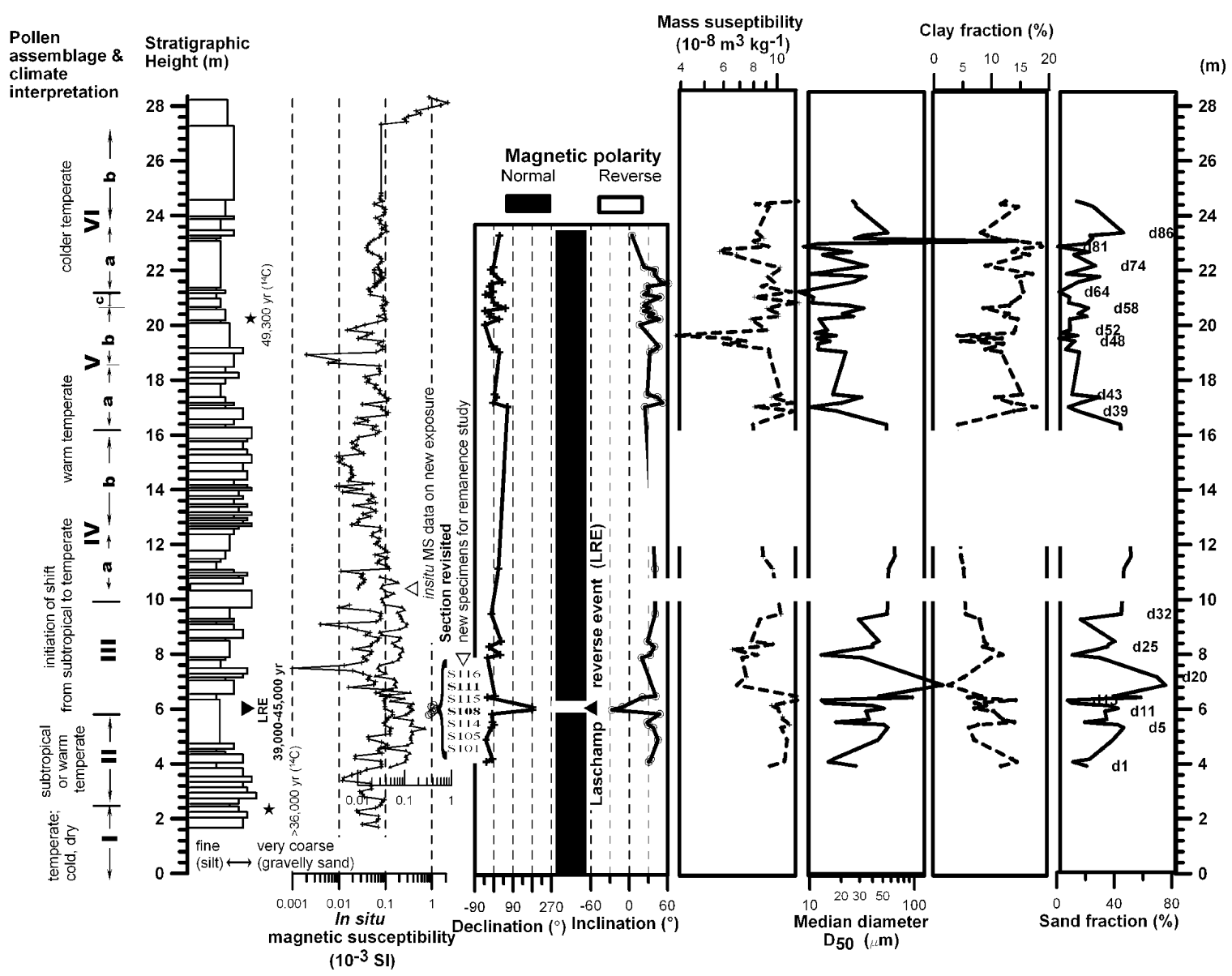

Fig. 2 The Dhapasi Section exposed NW of Basundhara, Ring Road. The columns arranged from left to right are as follows: (i) Lithological variation shown as horizontal bars approximately proportional to grain size accompanied by pollen assemblage data after Paudayal (2006); intervals of silt around 4.5-6 m and 20-23 m belong to prodelta deposits, whereas the rest belong to fluvial (e.g., near the top around $26 \mathrm{~m}$ ) and delta front deposits, as mentioned in column given in Fig. 1; (ii) Magnetic susceptibility (in situ volume susceptibility); (iii) Magnetic polarity zonation; (iv) Mass-specific susceptibility measured on discrete specimens; (v)-(vii) selected grain size parameters (median diameter, \% clay fraction, and \% sand fraction) for samples subjected to laser granulometry. Note the thin interval marked by reverse polarity labeled LRE. Five specimens from $<0.20 \mathrm{~m}$ interval collected during two field campaigns (2006 \& 2008) exhibit dual polarity (see Fig. 6). The reverse polarity is attributed to the Laschamp Reversal Event or Excursion (LRE) dated at ca. 39-45 Ka (Champion et al. 1988) or more narrowly at $41 \pm 1 \mathrm{Ka}$ (Lund et al. 2006)

the top of the section. Those pollen/paleoclimatic zones have been interpolated to the newly measured section (Fig. 2, extreme left), which will be used to present the results of our in situ measurements and laboratory studies related to magnetism and granulometry given below.

\section{In situ Magnetic Susceptibility (MS)}

Magnetic susceptibility (volume MS; $\kappa$ expressed hereafter in $10^{-3} \mathrm{SI}$ ) of the natural sediments was measured at the outcrop at $0.1 \mathrm{~m}$ spacing along the vertical section using a SM-30 pocket-sized magnetic susceptibility meter (sensitivity: $1 \times 10^{-7} \mathrm{SI}$; operating frequency: $8 \mathrm{kHz}$ ) by $\mathrm{ZH}$ Instruments. For natural section, values of $\kappa$ range between 0.001 and 0.15 , with lower range $(<0.02)$ being restricted to coarse sand layers that are very rich in quartz (Fig. 2). Within the $0.2 \mathrm{~m}$ thick uppermost sediment interval that shows traces of anthropogenic activities, $\kappa$ gradually increases from 0.15 to 2 . Besides the spike in MS 
caused by human-induced disturbance, prominent lithology-dependent variability of MS found to be inversely proportional to the grain size, makes it suitable for rapid screening of the vertical sediment sections and their lithostratigraphic interpretation especially in terms of broad grain-size classes.

\section{Laser granulometry}

Seventy six specimens of fine-grained sediments spaced mostly $0.1 \mathrm{~m}$ apart along the vertical were measured by Shimadzu Laser Diffraction Particle Size Analyzer (Model SALD-3000S) at Shimane University. These sediments constitute relatively thick prodelta deposits as well as relatively thin layers as a part of the package of floodplain deposits (cf. lithological columns in Figs. 1c \& 2).

Grain size data were analyzed first using SALD3000-WJA2:V1.21 software and then using Blott's GRADISTAT v.4 program (Blott and Pye 2001). Results of analyses are listed in Table 1 and plots of some selected parameters shown in Fig. 2. Analytical dataset leads to the following ranges for grain size parameters for the fine-grained sediments of the Dhapasi section: (i) median diameter (D50, $\mu \mathrm{m})$ : 10-60; (ii) clay fraction (\%): 5-20 ; (iii) sand fraction (\%): 5-40. The gradistat analysis shows the majority (ca. $70 \%$ ) of specimens to be polymodal ( $>3$ modes), with the rest being mostly trimodal with common modes of $0.45,7.3$ and $57.5 \mu \mathrm{m}$. Three representative specimens, that yield similar results when modeled for Gaussian lognormal distributions (Fig. 3), confirm the presence of 3-5 significant modes with distinct dispersion parameters. In the sand-clay-silt triangular diagram, the specimens plot predominantly in sandy silt area, followed by silt except for a few falling into the silty sand area (Fig. 4.).

The finest fraction $($ mode $=0.45 \mu \mathrm{m})$ contributing up to $<11 \%$ of total volume found in many specimens might be a measurement artifact caused by the lack of precise adjustment in the diffraction rate and is not considered further. Neglecting this mode doesn't influence the overall interpretation except that the number of significant modes will be lower (2 to 4). The prodelta deposits seem to be distinct from others in that they yield relatively consistent values of the selected parameters. Their intervals at ca. $20-23 \mathrm{~m}$ and 4.5-6 m, however, show significant differences in the parametric values. The former (upper or younger interval) is finer (in general, clay: $15 \%$, sand: $20 \%$, median diameter: $10-30 \mu \mathrm{m}$ ) than the latter (lower or older interval; clay: $7 \%$, sand: $40 \%$, median diameter: $40-50 \mu \mathrm{m}$ ). Despite relatively higher fluctuations in the grain size parameters of the sediments from the flood plain deposits, it is important to note that parametric values identical to one of these prodelta intervals are not uncommon implying that the discrimination of the fine-grained layers in terms of their affinity to prodelta and flood plain facies based solely on grain size parameters is not possible.

\section{Relationship between magnetic susceptibility} and the grain-size parameters

In order to examine any correlation between susceptibility and fine-scale variations in grain size, all samples analyzed for grain size were measured for volume susceptibility by AGICO Kappabridge (KLY-3) and normalized by mass to obtain massspecific MS $\left(\chi\right.$, expressed in $\left.10^{-8} \mathrm{~m}^{3} \mathrm{~kg}^{-1}\right)$. Although the results shown in Fig. 2 (left part) reveal inverse correlation of MS $(\kappa)$ with broad grain size classes (i.e., increasing trend from sand through silt to clay), $\chi$ vs. percent silt fraction implies that such relationship is not that obvious (Fig. 5).

\section{Magnetic polarity stratigraphy}

The age of Gokarna Formation has been inferred from ${ }^{14} \mathrm{C}$ radiometric dating to vary widely somewhere between ca. 50 and $34 \mathrm{Ka}$ (see a summary in Gautam 2001, and Table 2 below). In order to constrain the age, basically by careful analysis for the occurrence of the Laschamp Reverse Polarity Event or Geomagnetic Excursion (LRE) within this particular section, oriented specimens of silt were subjected to measurement of the magnetic remanence.

Natural remanent magnetization and magnetization intensity remaining after stepwise alternating field demagnetization were measured using $2 \mathrm{G}$ squid magnetometers at Tuebingen University and Kochi Core Center, Japan. After ensuring that an unstable magnetic component was commonly erased below 20-30 $\mathrm{mT}$, the magnetization direction obtained after demagnetization at 25 or $30 \mathrm{mT}$ was commonly used to determine the magnetic polarity. The plots in central 
Table 1: A condensed summary of grain-size analysis using Gradistat v. 4.0 by S. Blott (Blott and Pye 2001) of the fine sediments of the Dhapasi section. Sample levels (m) correspond to the section in Fig. 2

\begin{tabular}{|c|c|c|c|c|c|c|c|c|c|c|c|}
\hline Sample & $\begin{array}{l}\text { Level } \\
\text { (m) }\end{array}$ & Sample type & Sediment name & $\begin{array}{l}\text { Skewness } \\
\text { ( Folk \& Ward) }\end{array}$ & Kurtosis & Mode 1 & $\begin{array}{r}\text { Mode } 2 \\
\quad(\mu \mathrm{m})\end{array}$ & Mode 3 & $\begin{array}{l}\text { D50 } \\
(\mu \mathrm{m})\end{array}$ & $\begin{array}{l}\% \text { Sand } \\
(100 \text { - \% Mud) }\end{array}$ & $\begin{array}{l}\% \text { Clay } \\
\text { (\% Mud - \% Silt) }\end{array}$ \\
\hline$\overline{\mathrm{dl}}$ & 3.95 & Polymodal, vps & vf Sandy vc Silt & vfsk & Lepto & 40.68 & 0.45 & 7.26 & 27.50 & $20.7 \%$ & $11.6 \%$ \\
\hline $\mathrm{d} 2$ & 4.1 & Trimodal, vps & vf Sandy c Silt & fsk & Meso & 24.19 & 7.26 & 0.45 & 15.09 & $11.4 \%$ & $14.3 \%$ \\
\hline d3 & 4.2 & Polymodal, vps & f Sandy c Silt & sym & Meso & 20.34 & 7.26 & 0.45 & 16.86 & $22.9 \%$ & $13.6 \%$ \\
\hline $\mathrm{d} 4$ & 4.9 & Trimodal, vps & vf Sandy vc Silt & vfsk & Lepto & 57.53 & 0.45 & 7.26 & 44.90 & $39.1 \%$ & $7.0 \%$ \\
\hline d5 & 5.35 & Trimodal, vps & vf Sandy vc Silt & fsk & Lepto & 68.41 & 0.45 & 7.26 & 55.64 & $46.5 \%$ & $6.1 \%$ \\
\hline $\mathrm{d} 6$ & 5.45 & Polymodal, vps & vf Sandy vc Silt & vfsk & v Lepto & 57.53 & 193.50 & 0.45 & 51.23 & $42.6 \%$ & $7.6 \%$ \\
\hline d7 & 5.55 & Polymodal, vps & vf Sandy c Silt & fsk & Meso & 28.76 & 0.45 & 96.75 & 17.77 & $19.3 \%$ & $13.9 \%$ \\
\hline $\mathrm{d} 8$ & 5.65 & Polymodal, vps & f Sandy vc Silt & vfsk & Lepto & 40.68 & 162.70 & 0.45 & 36.87 & $34.5 \%$ & $12.0 \%$ \\
\hline $\mathrm{d} 10$ & 5.75 & Polymodal, vps & vf Sandy vc Silt & vfsk & Lepto & 115.10 & 40.68 & 0.45 & 29.39 & $25.7 \%$ & $11.7 \%$ \\
\hline d11 & 5.95 & Polymodal, vps & vf Sandy vc Silt & vfsk & Lepto & 48.38 & 162.70 & 0.45 & 34.56 & $33.6 \%$ & $10.3 \%$ \\
\hline $\mathrm{d} 12$ & 6.05 & Polymodal, vps & vf Sandy vc Silt & vfsk & v Lepto & 57.53 & 162.70 & 0.45 & 51.14 & $42.6 \%$ & $7.0 \%$ \\
\hline $\mathrm{d} 13$ & 6.15 & Polymodal, vps & vf Sandy vc Silt & vfsk & Lepto & 48.38 & 162.70 & 0.45 & 40.18 & $35.9 \%$ & $9.0 \%$ \\
\hline d14 & 6.25 & Trimodal, ps & vf Sandy c Silt & sym & Meso & 7.26 & 17.10 & 5.09 & 13.92 & $10.3 \%$ & $7.1 \%$ \\
\hline d15 & 6.35 & Trimodal, vps & c Silt & fsk & Lepto & 20.34 & 7.26 & 0.45 & 12.97 & $7.4 \%$ & $14.2 \%$ \\
\hline d16 & 6.45 & Polymodal, vps & vc Silty m Sand & vfsk & Lepto & 325.40 & 48.38 & 0.45 & 95.87 & $58.2 \%$ & $5.9 \%$ \\
\hline d17 & 6.5 & Polymodal, vps & vf Sandy vc Silt & fsk & Lepto & 48.38 & 193.50 & 0.45 & 45.92 & $40.0 \%$ & $8.2 \%$ \\
\hline d18 & 6.9 & Bimodal, ps & vc Silty c Sand & fsk & Platy & 774.00 & 81.36 & & 187.10 & $75.4 \%$ & $2.5 \%$ \\
\hline d20 & 7.2 & Bimodal, vps & vc Silty f Sand & vfsk & v Lepto & 162.70 & 0.45 & & 108.50 & $69.5 \%$ & $5.3 \%$ \\
\hline $\mathrm{d} 21$ & 7.9 & Polymodal, vps & vf Sandy vc Silt & fsk & Lepto & 40.68 & 162.70 & 0.45 & 31.63 & $30.0 \%$ & $9.8 \%$ \\
\hline d22 & 8 & Polymodal, vps & vf Sandy c Silt & fsk & Meso & 7.26 & 17.10 & 5.09 & 12.86 & $10.9 \%$ & $11.9 \%$ \\
\hline d 24 & 8.2 & Polymodal, vps & f Sandy vc Silt & fsk & Meso & 34.21 & 162.70 & 7.26 & 25.66 & $27.8 \%$ & $10.1 \%$ \\
\hline $\mathrm{d} 25$ & 8.3 & Polymodal, vps & vf Sandy vc Silt & vfsk & Lepto & 48.38 & 162.70 & 0.45 & 40.03 & $35.3 \%$ & $8.5 \%$ \\
\hline $\mathrm{d} 26$ & 8.4 & Polymodal, vps & f Sandy vc Silt & fsk & Lepto & 162.70 & 40.68 & 0.45 & 39.99 & $36.3 \%$ & $9.1 \%$ \\
\hline d27 & 8.5 & Polymodal, vps & vf Sandy vc Silt & vfsk & Lepto & 48.38 & 193.50 & 0.45 & 45.74 & $40.4 \%$ & $8.8 \%$ \\
\hline $\mathrm{d} 30$ & 9.3 & Trimodal, ps & vf Sandy vc Silt & vfsk & v Lepto & 40.68 & 0.45 & 7.26 & 29.35 & $16.6 \%$ & $7.9 \%$ \\
\hline d32 & 9.5 & Trimodal, ps & vf Sandy vc Silt & fsk & Lepto & 57.53 & 0.45 & 7.26 & 54.95 & $45.0 \%$ & $5.5 \%$ \\
\hline d34 & 11.15 & Polymodal, vps & vf Sandy vc Silt & fsk & Lepto & 57.53 & 162.70 & 0.45 & 56.67 & $46.7 \%$ & $5.1 \%$ \\
\hline d35 & 11.3 & Polymodal, vps & vf Sandy vc Silt & vfsk & v Lepto & 48.38 & 162.70 & 0.45 & 36.68 & $26.4 \%$ & $6.8 \%$ \\
\hline $\mathrm{d} 36$ & 11.45 & Trimodal, vps & vf Sandy vc Silt & fsk & v Lepto & 48.38 & 0.45 & 7.26 & 52.54 & $42.9 \%$ & $5.5 \%$ \\
\hline $\mathrm{d} 37$ & 11.6 & Bimodal, ps & vc Silty vf Sand & fsk & Lepto & 68.41 & 0.45 & & 65.27 & $51.7 \%$ & $4.7 \%$ \\
\hline d 38 & 16.4 & Trimodal, ps & vf Sandy vc Silt & fsk & Lepto & 57.53 & 0.45 & 7.26 & 54.23 & $44.3 \%$ & $4.1 \%$ \\
\hline d39 & 16.9 & Polymodal, vps & vf Sandy vc Silt & vfsk & Meso & 40.68 & 0.45 & 7.26 & 18.05 & $14.6 \%$ & $13.8 \%$ \\
\hline $\mathrm{d} 40$ & 17.05 & Polymodal, vps & c Silt & fsk & Meso & 7.26 & 0.45 & 12.09 & 9.99 & $8.1 \%$ & $17.8 \%$ \\
\hline $\mathrm{d} 41$ & 17.2 & Polymodal, vps & vf Sandy c Silt & fsk & Lepto & 34.21 & 0.45 & 7.26 & 20.15 & $16.4 \%$ & $13.4 \%$ \\
\hline $\mathrm{d} 42$ & 17.4 & Polymodal, vps & vf Sandy vc Silt & vfsk & Lepto & 136.80 & 48.38 & 0.45 & 31.42 & $29.7 \%$ & $10.6 \%$ \\
\hline $\mathrm{d} 43$ & 17.5 & Trimodal, vps & vf Sandy vc Silt & vfsk & Meso & 34.21 & 0.45 & 7.26 & 16.61 & $10.6 \%$ & $15.3 \%$ \\
\hline d44 & 19.05 & Polymodal, vps & vf Sandy vc Silt & vfsk & Lepto & 40.68 & 7.26 & 0.45 & 22.13 & $15.8 \%$ & $11.7 \%$ \\
\hline $\mathrm{d} 45$ & 19.15 & Trimodal, ps & c Silt & sym & Meso & 7.26 & 12.09 & 5.09 & 11.95 & $6.3 \%$ & $8.9 \%$ \\
\hline d47 & 19.35 & Polymodal, vps & vf Sandy m Silt & fsk & Lepto & 7.26 & 12.09 & 0.45 & 12.11 & $10.2 \%$ & $12.0 \%$ \\
\hline $\mathrm{d} 48$ & 19.45 & Trimodal, ps & vf Sandy c Silt & sym & Meso & 17.10 & 7.26 & 115.10 & 15.60 & $12.6 \%$ & $4.7 \%$ \\
\hline d49 & 19.55 & Trimodal, ps & c Silt & fsk & Lepto & 17.10 & 7.26 & 0.45 & 11.65 & $1.5 \%$ & $11.8 \%$ \\
\hline $\mathrm{d} 50$ & 19.65 & Trimodal, ps & vf Sandy c Silt & sym & Meso & 17.10 & 7.26 & 115.10 & 17.86 & $14.4 \%$ & $4.1 \%$ \\
\hline d51 & 19.75 & Trimodal, ps & $\mathrm{m}$ Silt & fsk & Lepto & 14.38 & 7.26 & 0.45 & 11.27 & $3.2 \%$ & $13.8 \%$ \\
\hline d52 & 19.85 & Trimodal, vps & c Silt & fsk & Lepto & 28.76 & 7.26 & 0.45 & 14.67 & $9.3 \%$ & $14.1 \%$ \\
\hline d54 & 20.25 & Polymodal, vps & c Silt & fsk & Meso & 7.26 & 14.38 & 0.45 & 12.25 & $9.1 \%$ & $14.5 \%$ \\
\hline d55 & 20.35 & Polymodal, vps & vf Sandy vc Silt & vfsk & Lepto & 34.21 & 0.45 & 115.10 & 26.00 & $21.0 \%$ & $12.2 \%$ \\
\hline $\mathrm{d} 56$ & 20.45 & Trimodal, vps & vf Sandy vc Silt & vfsk & Lepto & 34.21 & 0.45 & 7.26 & 20.50 & $14.9 \%$ & $13.0 \%$ \\
\hline $\mathrm{d} 58$ & 20.65 & Trimodal, vps & vf Sandy vc Silt & vfsk & v Lepto & 48.38 & 0.45 & 7.26 & 32.80 & $22.1 \%$ & $8.6 \%$ \\
\hline d59 & 20.75 & Polymodal, vps & vf Sandy vc Silt & vfsk & Lepto & 40.68 & 0.45 & 7.26 & 23.96 & $16.6 \%$ & $13.0 \%$ \\
\hline $\mathrm{d} 60$ & 20.85 & Polymodal, vps & m Silt & fsk & Lepto & 7.26 & 10.17 & 5.09 & 10.56 & $8.4 \%$ & $13.5 \%$ \\
\hline d61 & 20.95 & Polymodal, ps & c Silt & sym & Meso & 7.26 & 14.38 & 28.76 & 12.32 & $9.3 \%$ & $10.5 \%$ \\
\hline $\mathrm{d} 62$ & 21.05 & Polymodal, vps & c Silt & fsk & Meso & 7.26 & 10.17 & 24.19 & 10.81 & $8.8 \%$ & $14.9 \%$ \\
\hline d64 & 21.25 & Polymodal, ps & m Silt & fsk & Meso & 7.26 & 10.17 & 5.09 & 7.89 & $1.6 \%$ & $15.5 \%$ \\
\hline d65 & 21.35 & Trimodal, ps & m Silt & sym & Meso & 7.26 & 10.17 & 5.09 & 8.67 & $0.7 \%$ & $11.1 \%$ \\
\hline d66 & 21.45 & Polymodal, ps & c Silt & fsk & Meso & 7.26 & 20.34 & 5.09 & 11.19 & $1.7 \%$ & $10.2 \%$ \\
\hline $\mathrm{d} 67$ & 21.5 & Polymodal, vps & vf Sandy vc Silt & fsk & Lepto & 40.68 & 0.45 & 162.70 & 27.85 & $24.9 \%$ & $11.7 \%$ \\
\hline $\mathrm{d} 68$ & 21.6 & Polymodal, vps & vf Sandy vc Silt & vfsk & Lepto & 48.38 & 0.45 & 7.26 & 25.97 & $15.0 \%$ & $15.0 \%$ \\
\hline d69 & 21.7 & Trimodal, vps & vf Sandy vc Silt & vfsk & Lepto & 40.68 & 0.45 & 7.26 & 31.63 & $23.2 \%$ & $8.5 \%$ \\
\hline d70 & 21.8 & Polymodal, vps & vf Sandy vc Silt & vfsk & Lepto & 115.10 & 48.38 & 0.45 & 34.37 & $29.9 \%$ & $14.3 \%$ \\
\hline d71 & 21.9 & Polymodal, vps & c Silt & fsk & Meso & 7.26 & 17.10 & 0.45 & 10.33 & $6.9 \%$ & $17.1 \%$ \\
\hline d72 & 22 & Polymodal, vps & vf Sandy vc Silt & vfsk & Meso & 34.21 & 0.45 & 7.26 & 19.84 & $12.6 \%$ & $16.5 \%$ \\
\hline d73 & 22.1 & Polymodal, vps & c Silt & vfsk & Meso & 34.21 & 0.45 & 7.26 & 16.06 & $6.3 \%$ & $16.1 \%$ \\
\hline d74 & 22.2 & Trimodal, vps & vf Sandy vc Silt & vfsk & Lepto & 48.38 & 0.45 & 7.26 & 35.11 & $26.8 \%$ & $9.0 \%$ \\
\hline d77 & 22.5 & Polymodal, vps & c Silt & vfsk & Meso & 48.38 & 28.76 & 0.45 & 15.15 & $2.4 \%$ & $16.9 \%$ \\
\hline d78 & 22.6 & Polymodal, vps & vf Sandy c Silt & fsk & Meso & 20.34 & 0.45 & 7.26 & 13.32 & $11.9 \%$ & $16.5 \%$ \\
\hline d79 & 22.7 & Polymodal, vps & vf Sandy vc Silt & vfsk & Meso & 40.68 & 115.10 & 0.45 & 24.93 & $22.6 \%$ & $13.7 \%$ \\
\hline $\mathrm{d} 80$ & 22.8 & Polymodal, vps & vf Sandy c Silt & fsk & Lepto & 34.21 & 7.26 & 0.45 & 15.43 & $11.9 \%$ & $14.5 \%$ \\
\hline $\mathrm{d} 81$ & 22.9 & Polymodal, vps & m Silt & fsk & Meso & 7.26 & 12.09 & 0.45 & 8.71 & $0.8 \%$ & $18.7 \%$ \\
\hline d82 & 23 & Polymodal, vps & vf Sandy m Silt & fsk & Meso & 115.10 & 0.45 & 7.26 & 12.18 & $20.8 \%$ & $18.4 \%$ \\
\hline $\mathrm{d} 83$ & 23.1 & Very Fine & & vfsk & Platy & 920.40 & & & 970.80 & & \\
\hline d84 & 23.2 & Polymodal, vps & f Sandy c Silt & fsk & Lepto & 34.21 & 193.50 & 0.45 & 26.72 & $24.9 \%$ & $10.7 \%$ \\
\hline d85 & 23.3 & Polymodal, vps & vf Sandy vc Silt & vfsk & Lepto & 40.68 & 96.75 & 0.45 & 32.64 & $23.1 \%$ & $9.3 \%$ \\
\hline $\mathrm{d} 86$ & 23.4 & Polymodal, vps & f Sandy vc Silt & fsk & Lepto & 48.38 & 230.10 & 0.45 & 55.58 & $46.4 \%$ & $8.2 \%$ \\
\hline d88 & 24.35 & Polymodal, vps & vf Sandy vc Silt & vfsk & Lepto & 40.68 & 0.45 & 136.80 & 27.69 & $25.5 \%$ & $14.6 \%$ \\
\hline d89 & 24.45 & Polymodal, vps & vf Sandy vc Silt & vfsk & Lepto & 40.68 & 0.45 & 7.26 & 27.50 & $20.7 \%$ & $11.6 \%$ \\
\hline d 90 & 24.55 & Trimodal, vps & vf Sandy vc Silt & vfsk & Lepto & 40.68 & 0.45 & 7.26 & 26.05 & $14.0 \%$ & $12.4 \%$ \\
\hline
\end{tabular}

Note: the columns and the abbreviations used in them are as follows. Column 1. d for the sample name stands for Dhapasi - the sampled location. Column 3 . ps: poorly sorted; vps:
very poorly sorted, Column 4. f: fine; vf: very fine; m: medium; c:coarse; vc: very coarse,Column 5 . sym: symmetric; fsk: finely skewed; vfsk: very finely skewed, Column 6 . Lepto: leptokurtic; Meso: mesokurtic; v: very; Platy: platykurtic 

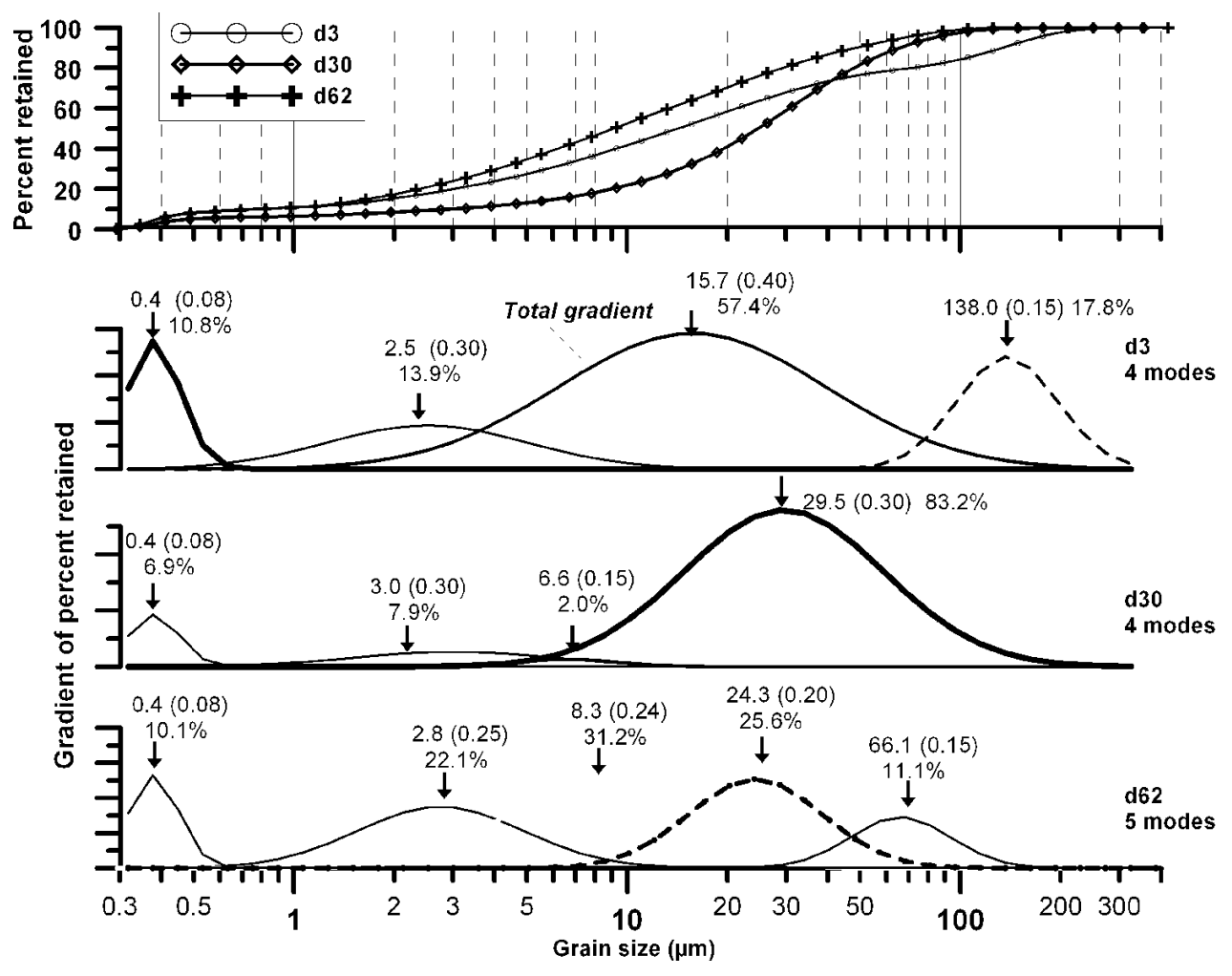

Fig. 3 Grain size gradient analysis to separate modal fractions. The uppermost graph shows the cumulative grain size distribution curves for 3 representative specimens. Logarithmic Gaussian distribution functions (Kruiver et al. 2001) model the curves in terms of 4-5 curves with shown modes (arrows), logarithmic dispersion parameters (in brackets) and contributions (\%). The finest mode seems to be a measurement artifact due to calibration problem and therefore will be ignored in further interpretation

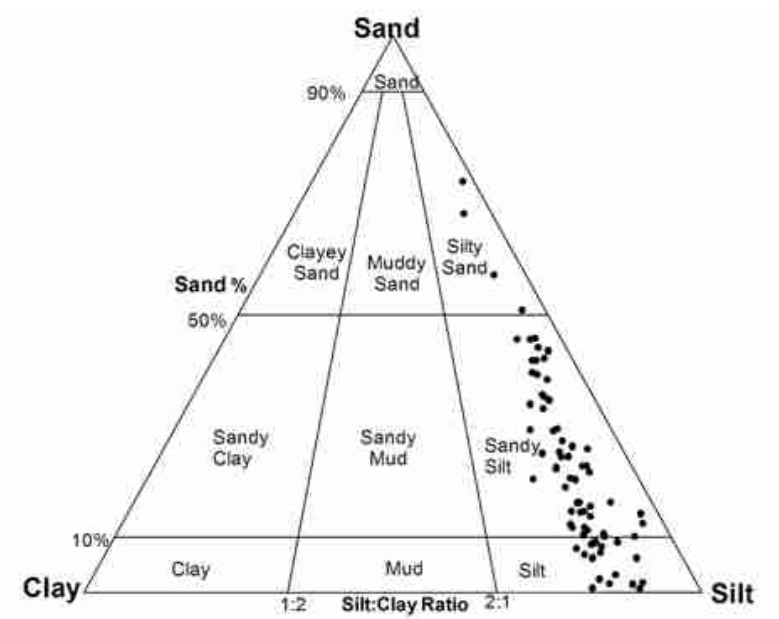

Fig. 4 Variation in grain size of the fine sediments from the Dhapasi Section. Note that majority of the specimens plot in the sandy silt and silt fields with several specimens in the silty sand field

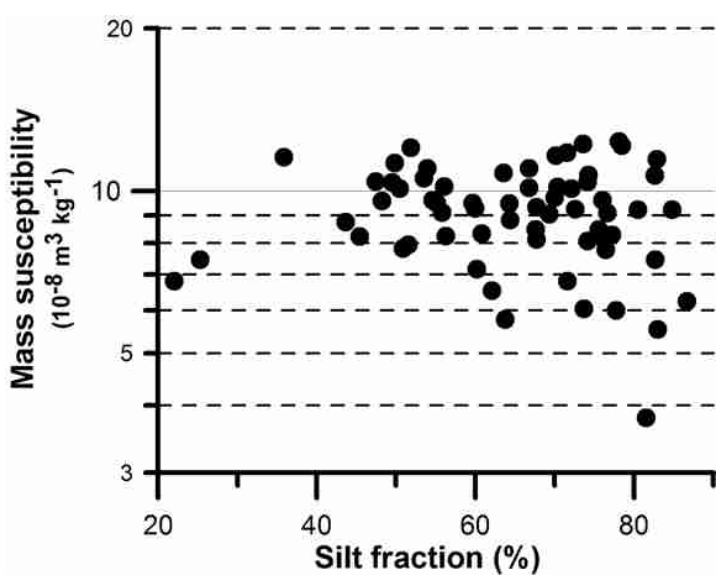

Fig. 5 Mass-specific MS vs. silt fraction (\%). The higher the percentage of silt fraction, the higher the susceptibility range 
Table 2: Some recent radiometric ${ }^{14} \mathrm{C}$ age data for the Gokarna Formation, Kathmandu Valley

\begin{tabular}{|c|c|c|c|}
\hline Location/section & $\begin{array}{l}\text { Age (years BP) } \\
\text { with error bars }\end{array}$ & $\begin{array}{l}\text { Author(s) or } \\
\text { Reference }\end{array}$ & Remarks \\
\hline Kapan & $44,900 \pm 1,100$ & $\begin{array}{l}\text { Sakai et al. (2009), in } \\
\text { prep. }\end{array}$ & - \\
\hline Dharmasthali & $35,500 \pm 500$ & $"$ & - \\
\hline ” & $43,300 \pm 300$ & $"$ & - \\
\hline 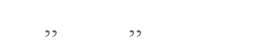 & $44,600 \pm 400$ & " & - \\
\hline Kapan & $47,600 \pm 1,500$ & " & Basal part of the section \\
\hline Mulpani, near Gokarna & $34,500 \pm 400$ & $"$ & Top of the Gokarna Fm. \\
\hline Gothatar, E of airport & $39,200 \pm 300$ & " & $\begin{array}{l}\text { Wood fragment from slump deposit } \\
\text { indicating lake level fall, at alt. } 1310 \mathrm{~m}\end{array}$ \\
\hline Dhapasi & $49,300 \pm 2100 / 1700$ & Paudayal (2006) & $\begin{array}{l}7 \mathrm{~m} \text { below the top (alt. ca. } 1,358 \mathrm{~m} \text { ) of } \\
\text { section. See Fig. 2, this paper, for approx. } \\
\text { height }\end{array}$ \\
\hline Dhapasi & $>36,100$ & Paudayal (2006) & $\begin{array}{l}\text { Ca. } 22.3 \mathrm{~m} \text { below top in the section } \\
\text { mentioned above }\end{array}$ \\
\hline
\end{tabular}

part of Fig. 2 show the polarity inferred using the 25 or $30 \mathrm{mT}$ data, except for a very thin interval (ca. $0.25 \mathrm{~m}$, at about $6 \mathrm{~m}$ above the base of the measured section) from which several specimens were found to exhibit great circle trends indicative of the composite nature of RM comprising normal (recent field) and reverse (primary field) polarity directions. Hence, Dhapasi section was revisited in 2008 to sample a new exposure near the base.
Resampling was carried out after confirming the match between the past section and the new exposure through new in situ MS measurements (compare the main MS curve with the short MS curve plotted at its side given in Fig. 2). Analysis to estimate the reverse polarity direction from the newly acquired dataset is shown in Fig. 6. The analytical results reveal the presence of a short reversely magnetized interval that can be attributed to the Laschamp Reversal Event

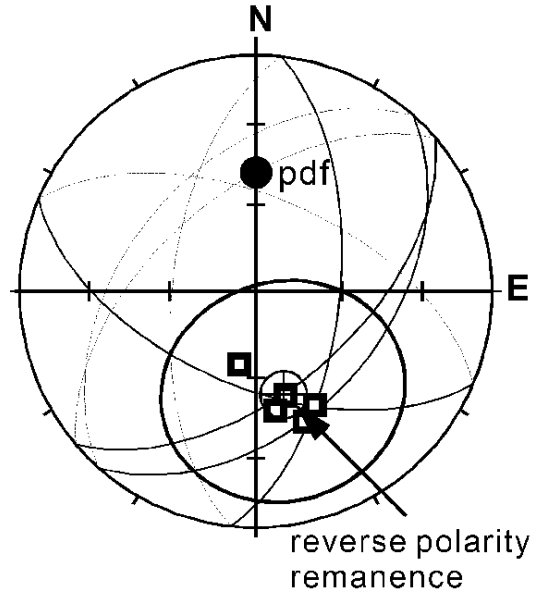

remanence

E
Data from Dhapasi lower reversed part for great circle analysis dec, inc data for poles

D12-1 203.0 33.0

D13-2 $319.7 \quad-34.4$

$\begin{array}{lll}\mathrm{S} 108 & 131.9 & 45.3\end{array}$

$\begin{array}{lll}\mathrm{S} 111 & 96.1 & 29.2\end{array}$

$\begin{array}{lll}\mathrm{S} 114 & 128.6 \quad 11.5\end{array}$

Great Circle Analysis for Sets:

Decl $=164.7^{\circ}, \quad$ Incl $=-51.4^{\circ}, \quad \mathrm{R}=4.91$,

Iterations $=11$, Alpha 95 $=4 \theta .7^{\circ}$

$\mathrm{k}=16.0, \mathrm{~N}$ (poles) $=5, \quad \mathrm{~N}$ (points $)=1$

Points on Planes:

$\begin{array}{ccc}\text { Pole Dec Inc } & \\ (203.0,33.0) & 165.5 & -50.7 \\ (319.7,-34.4) & 165.6 & -52.7 \\ (131.9,45.3) & 159.2 & -41.3 \\ (96.1,29.2) & 152.4 & -44.8 \\ (128.6,11.5) & 193.4 & -64.4\end{array}$

Fig. 6 Great circle analysis to estimate the reverse polarity remanence. Solid circle (upper part) is the present day field direction $\left(\mathrm{D}=0^{\circ}, \mathrm{I}=47^{\circ}\right)$ in Kathmandu. The open circle with confidence ellipse (lower part) is the mean estimate from the intersection of circles, whereas the squares are the projections of the mean estimate in each of the great circles. Analysis done using the pmagtool software from CEMP systems (M. Hounslow, Liverpool) 
or geomagnetic excursion (LRE) dated in literature in between ca. 39 to $45 \mathrm{Ka}$ (Champion et al. 1988) or more narrowly at $41 \pm 1 \mathrm{Ka}$ (Excursion $3 \beta$ : Laschamp excursion, recorded from Europe/Arctic and holes 172, 202; Lund et al. 2006).

\section{Magnetic mineralogy}

Several specimens were subjected to stepwise isothermal remanent magnetization (IRM) acquisition using magnetic pulses of up to $2.5 \mathrm{~T}$. The aim was to study the saturation remanence characteristics of the constituent magnetic phases and thereby extract information on magnetic minerals corresponding to them. Results for two representative specimens, which possessed rather strong initial NRM, are presented in Fig. 7. Gradient analysis of IRM acquisition curves (corresponding to saturation IRM or SIRM curves as the samples studied are completely saturated) following the method of Kruiver (2001) reveals the main magnetic minerals (median acquisition field $\left.\mathrm{B}_{1 / 2}\right)$ as follows: magnetite $(1.48 \mathrm{mT})$, maghemite (1.95-2.02 mT), hematite (2.80-2.90 mT) and possibly

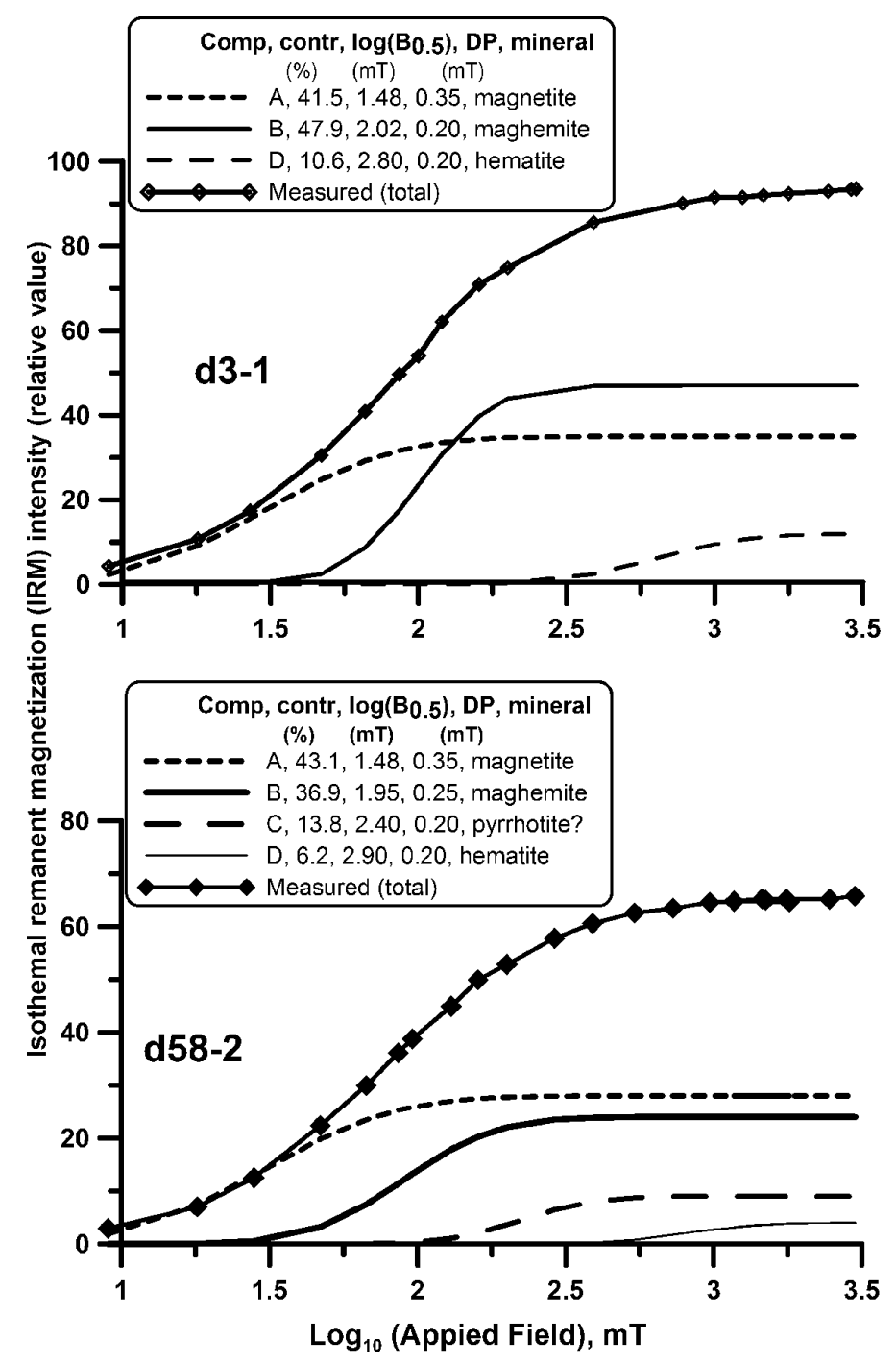

Fig. 7 Magnetic mineralogy deduced from IRM component analysis. Sample d3 has 3 components (A: magnetite, B:maghemite, D: hematite), whereas d58 contains additionally pyrrhotite or greigite 
pyrrhotite or greigite (2.40 mT). Contribution of hard coercivity mineral (hematite) to total IRM (is $6-8 \%$ meaning that it is probably the major magnetic mineral in terms of concentration as inferred also from previous magnetic studies of sediments from the Kathmandu Valley (Gautam et al. 2001).

\section{Anisotropy of the magnetic susceptibility (AMS) and depositional fabric}

AMS measurements were made on fine-grained sediment specimens already subjected to RM measurements acquiring a set of susceptibility data for 15 different positions using the Kappabridge (AGICO Inc., KLY-3) at Kochi Core Center (for details of methodology and interpretation, see Gautam and Rösler 1999; Goddu et al. 2007). The results reveal a magnetic fabric characterized by magnetic foliation subparallel to the bedding plane (paleohorizontal, predominantly oblate susceptibility ellipsoids $(\mathrm{T}>0)$, low absolute susceptibility magnitudes (ca. 10-4 $\mathrm{SI}$ ) that collectively point to the depositional fabric contributed by paramagnetic minerals (e.g., phyllosilicates) (Fig. 8). Magnetic

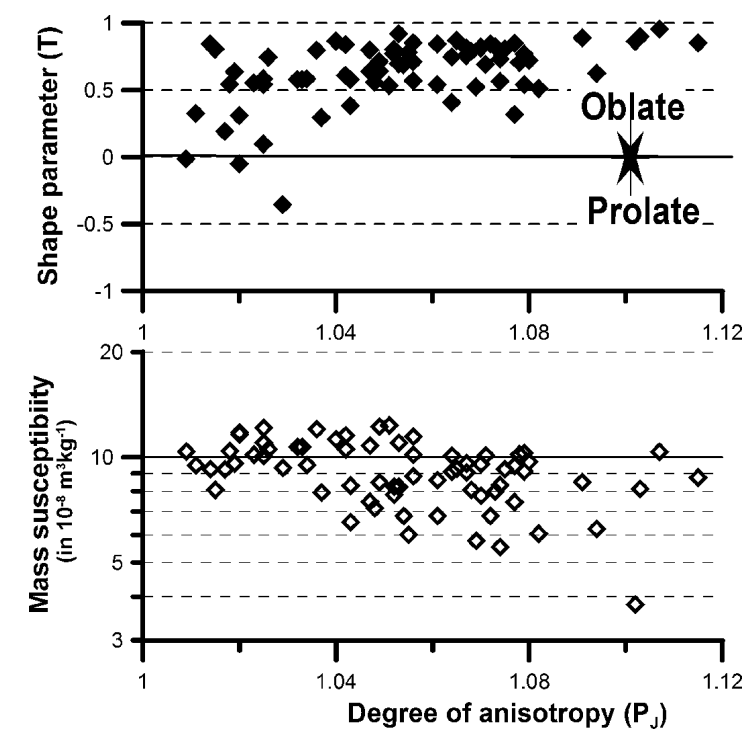

Fig. 8 Relationship of the mass-specific magnetic susceptibility and the shape parameter $(\mathrm{T})$ with the degree of anisotropy $\left(\mathrm{P}_{\mathrm{J}}\right.$, after Jelinek) for fine-grained sediments from Dhapasi section. Specimens with higher $\mathrm{P}_{\mathrm{J}}$ exhibit larger variation in susceptibility but more restricted and highly oblate shapes lineation, as shown by the maximum susceptibility axes $\left(\kappa_{\max }\right)$, is predominantly from NNW to SSE (peak trend: Azimuth $=324^{\circ}$, plunge $=15^{\circ}$ ) below ca $18-\mathrm{m}$ level in the Dhapasi section. Above the 18-m level, the magnetic lineation is basically from NNE to SSW (peak trend: Azimuth $=229^{\circ}$, plunge $=7.3^{\circ}$; despite the observed slight plunge to SSW the flow direction is inferred to be from NNE) and thus is almost perpendicular to that in the lower part (Fig. 9). Such a shift in the lineation trend is likely caused by differences in paleoflow direction during the respective sediment deposition intervals implying the occurrence of a significant change in palaeodrainage configuration.

\section{DISCUSSION AND CONCLUSION}

The fluvio-deltaic sediments of the Kathmandu Basin group in the Northern part of the Kathmandu valley exhibit significant variations in MS. For Dhapasi section represented by the Gokarna Formation, MS $\left(\kappa\right.$; in $10^{-3} \mathrm{SI}$ ) ranges from 0.001 to 0.15 for natural sediments such that rapid and effective susceptibility logging of several such sections and their mutual correlation become possible.

Laser granulometry data reveal polymodal (up to 4 modes) of the gain size distribution with 2 significant modes at 57.5 and $7.3 \mu \mathrm{m}$. The fine-grained sediments belong basically to sandy silt and silt classes in triangular diagram. Although it is difficult to explain the polymodal distribution pattern, the plausible mechanisms are: (i) contribution of mica grains, which are abundant in the source area lying in the northern part of the Kathmandu valley; simultaneous accumulation of rounded fine particles and platy grains of larger micas lead to multimodal distribution; (ii) post-depositional mixing of sediments (with differing modes) due to biological processes such as root intrusion, burrowing or dewatering; and (iii) mixed nature of sediments as a result of accumulation from multiple and asynchronous flow events. The fine-grained sediments of the flood plain deposits, though characterized by much variability of grainsize parameters compared to the prodelta deposits, can't be clearly distinguished from the prodelta deposits. This is because the latter show distinct differences at two widely separated levels despite consistency in grain size parameters in each level. 


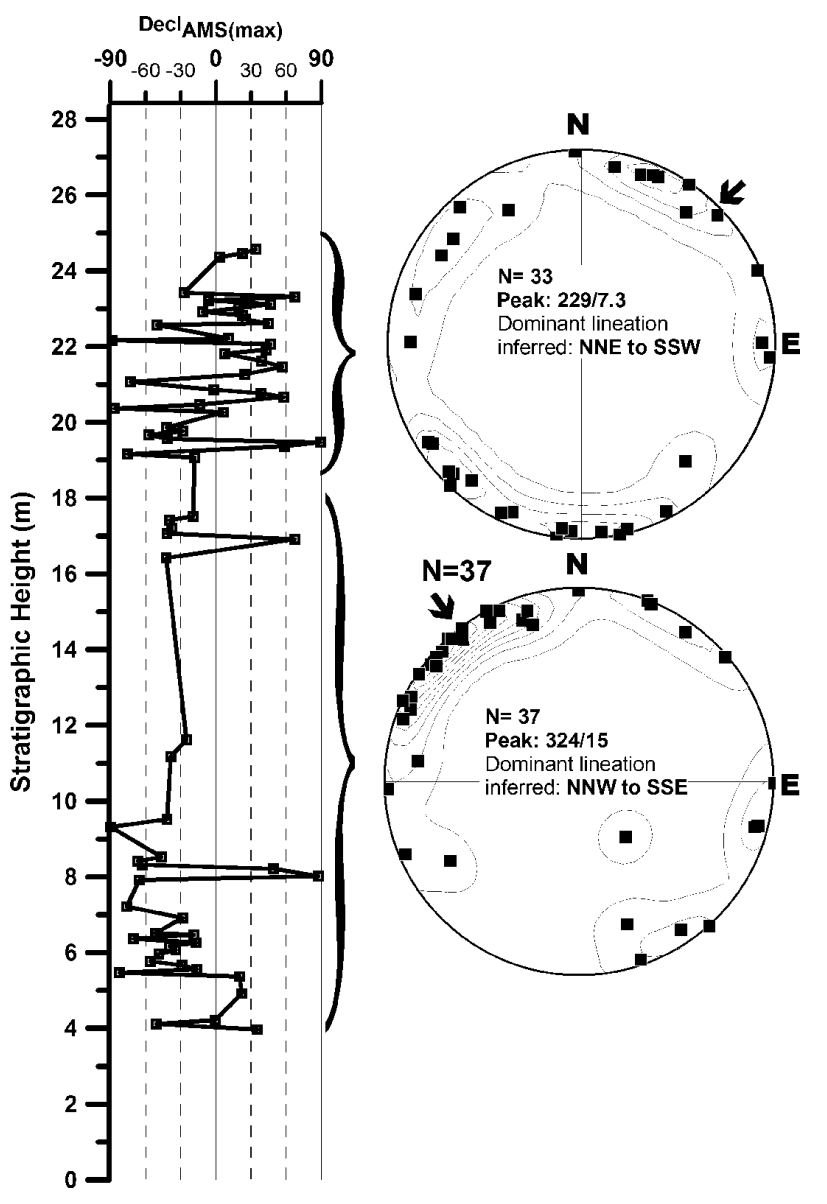

Fig. 9 Change in azimuth of magnetic lineation (declination of maximum susceptibility) versus stratigraphic height for Dhapasi section (left) and stereograms showing the downward pointing directions in lower-hemisphere (right). The azimuth remains essentially NW-SE below ca. $18 \mathrm{~m}$ but above that changes to predominantly $\mathrm{N}-\mathrm{S}$ to NNE-SSW. The magnetic lineation is equated to the paleocurrent direction during the sediment deposition.

The absence of distinct differences is due probably to the same sediment transport mode (i.e. suspension) by flood flow to the flood plain and prodelta regimes.

Magnetic lineations suggest differences in the paleocurrent directions below and above ca. $18 \mathrm{~m}$ of the Dhapasi section. This phenomenon and the differences in grain-size parameters of prodelta deposits at two levels (falling below and above ca. $18 \mathrm{~m}$ ) may be genetically related. These changes probably reflect the differences in the age-dependent paleodrainage configurations and source-sink variables (composition, distance of transport, etc.).
Measurements of the magnetic remanence for Dhapasi section reveal mostly normal polarity with an exception of the presence of a short interval (ca. $0.25 \mathrm{~m}$ thick, within the ca. $0.80 \mathrm{~m}$ thick silt near the base) that can be attributed to Laschamp Reversal Event or Excursion (LRE) dated variably between 39 and $45 \mathrm{Ka}$. This new reverse polarity finding along with recent ${ }^{14} \mathrm{C}$ dates lend further support to validity of $>45-34 \mathrm{Ka}$ age range for, and the affinity of the Dhapasi section to the Gokarna Formation.

\section{ACKNOWLEDGEMENTS}

This research was funded through a JSPS Grantin-aid for scientific research (kiban kenkyú C, No. 17540427) led by PG and the manuscript was completed during his affiliation to Hokkaido University Museum as a Research Fellow. Critical comments by Naresh K. Tamrakar helped improve the manuscript. The authors gratefully acknowledge the use of the magnetic measurements facilities at Kochi Core Center (Japan) and the University of Tuebingen (Germany), and also the sedimentological laboratory of Shimane University (Japan) for laser granulometry measurements.

\section{REFERENCES}

Blott, S. J. and Pye, K., 2001. GRADISTAT: A grain size distribution and statistics package for the analysis of unconsolidated sediments. Earth Surf. Process. Landforms, v. 26, pp. 1237-1248. doi:10.1002/esp.261

Champion, D. E., Lanphere, M. A. and Kuntz, M. A., 1988. Evidence for a new geomagnetic reversal from lava flows in Idaho: Discussion of short polarity reversals in the Brunhes and Late Matuyama polarity chrons. J. Geophys. Res., v. 93, pp. 11667-11680. doi:10.1029/JB093iB10p11667

Department of Mines and Geology (DMG), Nepal, 1980. Geological Map of Kathmandu Area and Central Mahabharat Range, 1:250 000 (compiled by J. Stöcklin, K. D. Bhattarai, and others). Ministry of Industry and Commerce, Kathmandu, Nepal.

Gautam, P., Hosoi, A., Sakai, T. and Arita, K., 2001. Magnetostratigraphic evidence for the occurrence of pre-Brunhes $(>780 \mathrm{kyr})$ sediments in the northwestern part of the Kathmandu Valley, Nepal. Jour. Nepal Geol. Soc., v. 25, pp. 99-109.

Gautam, P. and Rösler, W., 1999. Depositional chronology and fabric of Siwalik Group sediments in central Nepal from magnetostratigraphy and magnetic anisotropy. In 
Geology of the Nepal Himalaya: Recent Advances (P. LeFort and B. N. Upreti, eds). J. Asian Earth Sci., v. 17, pp. 659-682.

Goddu, S. R., Appel, E., Gautam, P., Oches, E. A. and Wehland, F., 2007. The lacustrine section at Lukundol, Kathmandu basin, Nepal: Dating and magnetic fabric aspects. J. Asian Earth Sci., v. 30, no.1, pp. 73-81. doi:10.1016/j.jseaes.2006.07.009

Kruiver, P. P., Dekkers, M. J., and Heslop, D., 2001. Quantification of magnetic coercivity components by the analysis of acquisition curves of isothermal remanent magnetization. Earth Planet. Sci. Lett., v. 189, pp. 269-276. doi:10.1016/S0012-821X(01)00367-3

Lund, S., Stoner, J. S., Channell, J. E. T., and Acton, G., 2006. A summary of Brunhes paleomagnetic field variability recorded in Ocean Drilling Program cores. Phys. Earth and Planetary Int., v. 156, pp. 194-204. doi:10.1016/j.pepi.2005.10.009

Paudayal, K. N., 2006. Late Pleistocene pollen assemblages from Gokarna Formation (Dhapasi section) in Kathmandu valley, Nepal. Jour. Nepal Geol. Soc., v. 33, pp. 33-38.
Sakai, H., 2001. Stratigraphic division and sedimentary facies of the Kathmandu Basin Group, central Nepal. Jour. Nepal Geol. Soc., v. 25, pp. 19-32.

Sakai H., Sakai H., Wataru Y., Fujii, R., Hayashi, T., and Upreti B. N., 2006. Pleistocene rapid uplift of the Himalayan frontal ranges recorded in the Kathmandu and Siwalik basins. Palaeogeography, Palaeoclimatology, Palaeoecology, v. 241, pp. 16-27. doi:10.1016/j.palaeo.2006.06.017

Sakai, T., Takagawa, T., Gajurel, A.P., Tabata, H., Ooi N., and Upreti, B.N., 2006. Discovery of sediments indicating rapid lake-level fall in the Late Pleistocene Gokarna Formation, Kathmandu Valley, Nepal: Implication for lake terrace formation. Daiyonki Kenkyuu (The Quaternary Research), v. 45, no.2, 99-112. doi:10.4116/jaqua.45.99

Yoshida, M. and Gautam, P., 1988. Magnetostratigraphy of Plio-Pleistocene Lacustrine Deposits in the Kathmandu Valley, Central Nepal. Proc. Indian National Sci. Acad., A, v. 54, no.3, pp. 410-417.

Yoshida, M. and Igarashi, Y., 1984. Neogene to Quaternary Lacustrine Sediments in the Kathmandu Valley, Nepal. Jour. Nepal Geol. Soc., v. 4 (Sp. Issue), pp. 73-100. 